\section{Correction: Occurrence of harmful algal species and shellfish toxicity in Sardinia (Italy)}

\author{
Anna Maria Bazzoni, ${ }^{1}$ \\ Alessandro Graziano Mudadu, ${ }^{1}$ \\ Giuseppa Lorenzoni, ${ }^{1}$ Igor Arras, ${ }^{1}$ \\ Antonella Lugliè, ${ }^{2}$ Barbara Vivaldi, ${ }^{3}$ \\ Valentina Ciccotelli, ${ }^{3}$ Giovanna Sanna, ${ }^{1}$ \\ Giuseppe Tedde, ${ }^{1}$ Salvatore Ledda, ${ }^{1}$ \\ Enrico Alesso, ${ }^{3}$ Edoardo Marongiu, ${ }^{1}$ \\ Sebastiano Virgilio ${ }^{1}$ \\ ${ }^{1}$ Institute for Experimental Veterinary \\ Medicine of Sardinia, Sassari; \\ ${ }^{2}$ University of Sassari, Sassari; ${ }^{3}$ Institute \\ for Experimental Veterinary Medicine of \\ Piedmont, Liguria and Valle D'Aosta, \\ Genoa, Italy
}

Anna Maria Bazzoni, Alessandro Graziano Mudadu, Giuseppa Lorenzoni, Igor Arras, Antonella Lugliè, Barbara Vivaldi, Valentina Cicotelli, Giovanna Sanna, Giuseppe Tedde, Salvatore Ledda, Enrico Alesso, Edoardo Marongiu, Sebastiano Virgilio (2016). Occurrence of harmful algal species and shellfish toxicity in Sardinia (Italy). Ital J Food Safety 5:6095.

Due to a technical error, Dr. Valentina Ciccotelli's name was erroneously mispelled as Valentina Cicotelli. The correct author's name (Valentina Ciccotelli) appears above and is provided in this PDF.
Correspondence: Anna Maria Bazzoni, Department of Food Hygiene, Institute for Experimental Veterinary Medicine of Sardinia, via Duca degli Abruzzi 8, 07100 Sassari, Italy.

Tel: +39.0792892348 - Fax: +39.0792892324

E-mail: bazzoni.annamaria@tiscali.it

Key words: Biotoxins; Potentially toxic microalgae; Shellfish farms; Mediterranean.

Received for publication: 3 April 2017.

Accepted for publication: 3 April 2017

This work is licensed under a Creative Commons Attribution-NonCommercial 4.0 International License (CC BY-NC 4.0).

(C) Copyright A.M. Bazzoni et al., 2017 Licensee PAGEPress, Italy

Italian Journal of Food Safety 2017; 6:6734 doi:10.4081/ijfs.2017.6734 